\title{
O SIGNIFICAdO CULTURAL ATRIBUído AO CENTRO de TERAPIA INTENSIVA POR CLIENTES E SEUS FAMILIARES: UM ELO ENTRE A BEIRA DO ABISMO E A LIBERDADE ${ }^{1}$
}

\author{
Rejane Cussi Assunção Lemos ${ }^{2}$ \\ Lídia Aparecida Rossi ${ }^{3}$
}

Lemos RCA, Rossi LA. O significado cultural atribuído ao centro de terapia intensiva por clientes e seus familiares: um elo entre a beira do abismo e a liberdade. Rev Latino-am Enfermagem 2002 maio-junho; 10(3):345-57.

Este estudo etnográfico teve como objetivo identificar os significados culturais que os clientes admitidos em Centro de Terapia Intensiva e seus familiares atribuem ao processo de hospitalização. Os dados foram coletados mediante a realização de observação participante e entrevistas com 17 sujeitos (clientes e seus familiares), durante a hospitalização. A partir da análise dos dados, surgiram três categorias: 1) CTI, a beira do abismo, um lugar desconhecido e assustador; 2) O elo entre a beira do abismo e a liberdade; 3) A alta do CTI: a liberdade para a vida. O tema central foi: "CTI, um elo entre a beira do abismo e a liberdade". Considerou-se relevante desvelar os significados culturais envolvidos nessa situação, o que poderá subsidiar uma assistência personalizada ao cliente e sua família.

DESCRITORES: cuidados de enfermagem, unidades de terapia intensiva, etnografia

\section{THE CULTURAL MEANING ATTRIBUTED TO THE INTENSIVE CARE UNIT BY CLIENTS AND THEIR PARENTS: A LINK BETWEEN ABYSM BORDER AND FREEDOM}

The purpose of this ethnographic study was to identify the cultural meaning that patients in an intensive care unit and their relatives attribute to the hospitalization process. Data were collected by means of participant observation and interviews with 17 participants (clients and their family), during hospitalization. Data were classified in tree categories: 1)ICU, the abysm border: a strange and scary place; 2) ICU: the link between the abysm border and freedom; 3) discharge from ICU: freedom of life. The main theme was: "Intensive Care Unit - a link between abysm border and freedom". Authors considered relevant to unveil the cultural meanings involved in the situation in order to provide elements for a personalized care to the client and family.

DESCRIPTORS: Nursing Care; Intensive Care Unit; Ethnography

\footnotetext{
${ }^{1}$ Extraído da dissertação de mestrado: "O Significado Cultural Atribuído ao Processo de Internação em Centro de Terapia Intensiva por Clientes e seus familiares: um elo entre a beira do abismo e a liberdade", ${ }^{2}$ Enfermeira, Professor do Departamento de Enfermagem na Assistência Hospitalar da Faculdade de Medicina do Triângulo Mineiro, Uberaba - Minas Gerais, e-mail: rjlemes@uol.com.br, ${ }^{3}$ Enfermeira, Professor Doutor da Escola de Enfermagem de Ribeirão Preto, da Universidade de São Paulo, Centro Colaborador da OMS para o desenvolvimento da pesquisa em enfermagem, e-mail: rizzardo@eerp.usp.br
} 


\section{EL SIGNIFICADO CULTURAL ATRIBUIDO AL PROCESO DE HOSPITALIZACIÓN EN CENTRO DE TERAPIA INTENSIVA POR CLIENTES Y SUS FAMILIARES: UN ESLABÓN ENTRE EL BORDE DEL ABISMO Y LA LIBERTAD}

Este estudio tiene como objetivo identificar los significados culturales que los clientes admitidos en Centro de Terapia Intensiva (CTI) y sus familiares atribuyen al proceso de hospitalización. Los datos fueron recogidos mediante la realización de observación participante y entrevistas con 17 participantes (clientes y sus familiares), durante la hospitalización. Del análisis de los datos emergieron tres categorías principales: 1) CTI, al borde del abismo: un sitio desconocido y asustador; 2) CTI: el eslabón entre el borde del abismo y la libertad; 3) El alta del CTI: la libertad para la vida. El tema central fue: "CTI: un eslabón entre el borde del abismo y la libertad". Se consideró relevante revelar los significados culturales envueltos en esta situación concediendo una asistencia personalizada al cliente y su familia.

DESCRIPTORES: cuidados de enfermería, unidad de cuidados intensivos, etnografía

\section{INTRODUÇÃO}

$\boldsymbol{O}$ cuidado de enfermagem é o ponto chave da hospitalização, uma vez que permite estabelecer intervenções terapêuticas centradas no cliente e, dessa forma, torna possível o aprimoramento de uma relação interpessoal enfermeiro-cliente. A hospitalização pode tornar-se um processo difícil e, ao mesmo tempo, pode ser caracterizada como uma situação natural da vida.

Assim, o Centro de Terapia Intensiva (CTI), apesar de oferecer serviço médico e paramédico especializado, com observação constante e equipamentos tecnológicos avançados e de alta precisão, talvez seja o local que mais gera estresse nos clientes e seus familiares. A movimentação das pessoas e o barulho monótono dos aparelhos contribuem para essa situação, que, certamente, compromete tanto os profissionais que atuam na unidade, quanto o próprio cliente e sua família $^{(1-2)}$. Além da própria estrutura física e ambiental do CTI, a doença contribui e interfere na capacidade de adaptação e mudança do cliente $^{(3)}$.

A família também sofre com a internação de um parente no CTI. Ela tem necessidade de informações relacionadas à internação, ao ambiente, ao risco de vida do seu ente, enfim, necessidades que geram estresse e que devem ser consideradas pelos profissionais durante toda a internação ${ }^{(4-6)}$.

Alguns estudos têm sido realizados com o objetivo de compreender as percepções do cliente e de sua família em relação à vivência no CTI. Dentre eles, ressaltamos: um trabalho que utilizou a abordagem etnográfica e fundamentou-se no interacionismo simbólico ${ }^{(7)}$; dois que fizeram uso da fenomenologia como opção metodológica ${ }^{(8-9)}$ e um que se fundamentou nas propostas de Lüdke e André para analisar os dados ${ }^{(10)}$.

Assim, este estudo teve como objetivo identificar os significados culturais atribuídos, pelos clientes e seus familiares, ao período de hospitalização no CTI. Para tanto, realizou-se um trabalho etnográfico cuja metodologia está descrita a seguir.

\section{METODOLOGIA}

A principal finalidade da etnografia é tentar compreender, por intermédio da cultura, 
o modo de vida do informante, a partir de seu próprio ponto de vista. A cultura pode ser considerada como um bloco de princípios, implícitos ou explícitos, que são herdados pelos membros de uma sociedade particular. Estes enfatizam a maneira de vida de um povo, o seu modo de ver o mundo, de vivenciá-lo emocionalmente, de comportar-se dentro dele em relação aos outros, a deuses ou a forças sobrenaturais e ao meio ambiente natural. Esses conjuntos de princípios são repassados de uma geração para a seguinte, por meio do sistema de símbolos, da linguagem, do ritual e da arte. A cultura pode ser considerada como uma "lente" herdada(11).

A situação social escolhida para o desenvolvimento desta pesquisa foi a dos clientes hospitalizados no Centro de Terapia Intensiva Adulto, do Hospital Escola da Faculdade de Medicina do Triângulo Mineiro, em Uberaba-MG, e os respectivos familiares, quando considerados informantes-chave.

A coleta dos dados foi realizada durante um período de seis meses, iniciado após a obtenção do consentimento do Comitê de Ética e Pesquisa, da Faculdade de Medicina do Triângulo Mineiro. Nesse período, foram entrevistados 17 informantes (clientes e familiares), que concordaram em participar do estudo, mediante obtenção do termo de consentimento livre e esclarecido, e que atenderam aos requisitos pré-estabelecidos: idade mínima de 21 anos, independente do sexo, que se comunicavam verbalmente e estavam orientados em relação ao tempo e ao espaço e residiam em Uberaba. O número de informantes não foi estabelecido previamente, assim a coleta dos dados ocorreu até que houvesse saturação das informações. Os clientes foram entrevistados nas enfermarias, ao receber alta do CTI, e os familiares, durante o processo de internação, após o horário de visitas.

Durante a realização do trabalho de campo, várias técnicas e estratégias podem estruturar a coleta dos dados. Duas técnicas consideradas relevantes foram utilizadas neste estudo: a observação participante e a entrevista $^{(12)}$. Na realização das observações participantes, optou-se por assumir o papel de observador como participante, no qual prevalece o caráter mais atuante do pesquisador, e os sujeitos são informados dos objetivos do estudo ${ }^{(13)}$.

A entrevista semi-estruturada foi a modalidade utilizada, orientada pelas questões: Clientes - Você já esteve em um CTI antes? O que você sentiu quando entrou pela primeira vez no CTI? e Para você, o que representou a internação em CTI? Familiares - Você já esteve em um CTI antes? O que você sentiu quando entrou pela primeira vez no CTI? Como foi para você ter seu parente internado no CTI?.

Utilizou-se um gravador para registro das informações obtidas por meio de entrevistas (com consentimento prévio dos entrevistados) e um diário de campo para a documentação dos dados oriundos das observações participantes.

O processo de análise aconteceu simultaneamente à coleta dos dados, ou seja, na medida em que esses foram coletados procedeu-se a sua análise. A partir da leitura inicial dos dados, foram identificados códigos que são rótulos utilizados para designar unidades de conteúdo. Estes variam de acordo com os dados coletados, sendo importantes, uma vez que permitem reproduzir dados concretos da realidade cultural em pauta ${ }^{(14)}$. Na 
etapa seguinte, os códigos similares foram comparados e agrupados em categorias, constituindo um grupo mais compacto de códigos. Posteriormente, essas categorias foram comparadas e agrupadas. A sua representação final consistiu no tema cultural $^{(14)}$. Os temas compõem o processo de teorização e recontextualização ${ }^{(13,15)}$.

Os dados foram interpretados de acordo com os Modelos Explicativos (MEs) para explicar as diferentes perspectivas sobre a doença ${ }^{(16)}$. Estes permitem compreender os traços cognitivos que permeiam o processo pelo qual a doença é padronizada, interpretada e tratada. O ME é definido como as noções relativas a determinado episódio de uma doença e seu tratamento, que são utilizadas por todos aqueles envolvidos em um processo clínico. O autor distingue os MEs utilizados pelos médicos e os MEs utilizados pelos doentes e suas famílias. Afirma que ambos oferecem explicações sobre como a doença e o tratamento são entendidos e vivenciados pela sociedade em foco e como esta realiza as escolhas entre as terapias e os terapeutas, permitindo, assim, a elaboração de um significado pessoal e social da experiência da doença. A interação entre os dois MEs é o que nos permite compreender como se desenvolve o processo de assistência à saúde, baseado nas crenças, normas de conduta e expectativas específicas que envolvem determinada sociedade $^{(16)}$.

\section{RESULTADOS E DISCUSSÃO}

A partir da análise dos dados, foram construídas três categorias descritas a seguir:
CTI, a beira do abismo: um lugar desconhecido e assustador

Nesta categoria, são apresentados os depoimentos de clientes do CTI e de seus familiares, os quais expressam o significado de vivenciar o CTI como ambiente desconhecido e estigmatizado. Nesse sentido, identificamos duas subcategorias a saber: o medo do desconhecido e o medo da morte.

O medo do desconhecido

A falta de informação e de conhecimento prévio em relação ao $\mathrm{CTI}$, bem como qual tipo de cliente atendido e quais as suas principais finalidades são aspectos que geram insegurança e medo. Nessa subcategoria, os depoimentos demonstram que os familiares e clientes desconhecem o CTI e suas rotinas, considerando-o como ambiente assustador.

... Eu achava que lá era o último lugar que a pessoa ia para se recuperar e que, se ela não recuperasse, morria. Era o último lugar do hospital na hora da morte ... Um doente, quando entrava, estava entre a vida e a morte (Cliente 12).

... achei minha mãe normal. Eu pensei que ela ia ficar diferente. Pensei que ela ia ficar meio boba, mas ela está normal (Família 13).

Pode-se inferir que a internação em CTI é uma fonte geradora de estresse para as pessoas que a vivenciam. Esses sentimentos são ressaltados pelo ambiente e por suas características físicas e estruturais que, na maioria das vezes, são desconhecidas dos clientes e de seus familiares ${ }^{(17-18)}$.

Conforme mostram os depoimentos, o estigma da internação em CTI é um fato marcante para os informantes. A cultura que as pessoas adquirem ao longo do tempo, sobre 
as características da internação em CTI, é vivenciada coletivamente e não se altera com informações pré-internação que, muitas vezes, não consideram a perspectiva do cliente e da família.

Durante a hospitalização, a falta de informação sobre o estado de saúde das pessoas e sobre os procedimentos revela como o cliente está exposto às decisões assumidas por outras pessoas em relação a questões que Ihe dizem respeito ${ }^{(19)}$. Assim, ocorre a alienação dos clientes em relação ao seu tratamento, sendo esses desrespeitados no direito que têm sobre sua doença e seu corpo. Em respeito ou receio à equipe multiprofissional eles se tornam passivos, destituídos de autonomia e responsabilidade ${ }^{(18)}$.

A utilização de termos específicos à determinada cultura pode gerar mal-entendidos e contribuir para a atribuição de significados diferentes para o médico e o cliente. $\mathrm{O}$ uso de terminologias afins, pode ser considerado como garantia de entendimento mútuo. A experiência da doença (enfermidade - illness) vivenciada pelo cliente e familiares envolve um processo de atenção, percepção, resposta direta afetiva, cognitiva e atribuição de valor à manifestação da doença, e resulta de comunicação e interação interpessoal no contexto da família e rede de troca de informações. A enfermidade é explicada por clientes e familiares a partir dos MEs estabelecidos em cada sistema cultural. O processo de doença (disease), na perspectiva do profissional de saúde, afeta um único indivíduo, mas a experiência da doença, muito freqüentemente, afetará todos os outros que convivem com essa pessoa, como, por exemplo, sua família, seus amigos, seus colegas de trabalho ${ }^{(16)}$. Assim, para que o tratamento tenha êxito, esse deve fazer sentido para os clientes, baseado em seus MEs. A interação entre os MEs possibilita uma melhor comunicação entre as pessoas, assim como melhora as interações oferecidas ao cliente, bem como o relacionamento entre equipe, cliente e família ${ }^{(14)}$.

Os clientes e seus familiares, de um lado, e os profissionais de saúde, de outro, convivem em realidades diferentes e possuem MEs distintos. Assim, muitas vezes, a informação é fornecida a partir da compreensão que o profissional tem do processo da doença (disease), mas não é compreendida por clientes e familiares, contribuindo para a manutenção do medo do desconhecido, que envolve o dia a dia dos clientes e familiares no CTI.

Ao fornecer as informações sobre rotinas, características do $\mathrm{CTI}$, finalidade de cada equipamento e funções específicas de cada membro da equipe, deve-se considerar o significado cultural da internação no CTI, atribuído por clientes e familiares.

\section{O medo da morte}

Essa subcategoria reúne depoimentos dos clientes e de seus familiares que expressam o medo da morte, relacionado, diretamente, com a hospitalização em CTI. Os relatos evidenciam o estigma impresso na palavra CTI. Demonstram como a questão da morte permeia culturalmente a noção préconcebida de estar internado em CTI. Para os informantes, o CTI significa estar entre a vida e a morte, pode ser uma ida sem volta.

... eu tinha medo de morrer ... porque, assim que eu entrei, morreu um. Ai eu apavorei: 'estou entrando e já está saindo um morto? Então, provavelmente, eu fico uns dias aqui e devo sair morta' (Cliente 10).

... para mim, a UTI significava vida ou morte ... 
Antigamente, estarna UTI era estar entre a vida e a morte, mais para a morte (Família 16).

Como se pode perceber, a cultura que permeia o entendimento dos clientes e sua família a respeito do significado da internação em CTI está diretamente relacionada à questão da morte. A morte parece permear os pensamentos e sentimentos da família.

Outro fato que chamou atenção foi a questão da permanência no CTI e do retorno a ele após a alta. Tanto o cliente como a família sentem medo quando se deparam com a possibilidade de hospitalização nesse ambiente, consideram a internação suficiente e referem a não pretensão em vivenciá-la novamente.

Mesmo após passarem pela experiência de internação no CTI, os clientes possuem uma visão estereotipada do local, vinculada à idéia de sofrimento e morte. No entanto, em contraposição, ao mesmo tempo, esforçam-se para considerar os aspectos positivos do setor $^{(20)}$.

Portanto, mais uma vez a questão da informação e do conhecimento antecipado, por parte dos profissionais de saúde, a respeito das crenças e valores do cliente e da família, aparecem como fatores decisivos para o atendimento direto das necessidades básicas dos clientes de CTI. Dessa forma, o estigma de morte eminente, vinculado à internação em CTI, somente poderá ser desmitificado quando esses aspectos forem trabalhados com o cliente e com a família, durante o processo de hospitalização no setor.

No CTI, o medo da morte está diretamente relacionado ao afastamento familiar. Essa separação é compreendida pelos clientes como fator gerador de insegurança e medo, pois é permeada de estresse. Assim, a ansiedade, a doença grave e o medo de morrer são fatores que propiciam o desenvolvimento do sentimento de isolamento do cliente da sua família.

A questão do isolamento social está diretamente relacionada com o afastamento do cliente de seus hábitos rotineiros, de sua família, e de seu mundo, fato esse que aparece nos relatos. Ao mesmo tempo em que os clientes entendem o isolamento social como rotina estabelecida pelo CTI, procuram justificar a importância da presença da família para seu conforto. Pode-se inferir que existe uma perspectiva cultural comum aos informantes acerca da presença da família no CTI, durante a hospitalização.

... o calor da família traz confiança, segurança para o paciente ... porque a pessoa tendo o familiar ali junto, é sinal de que ele não está sendo abandonado. $O$ medo fica menor (Cliente 8).

O isolamento social é uma das principais causas de ansiedade para o cliente de CTI e para sua família. O cliente isolado tende a incluir-se, retirar-se, ou distanciar-se emocionalmente, quando se vê cercado por pessoas ativas e ocupadas, uma vez que ele apresenta poucos recursos disponíveis para reduzir a sensação de isolamento ${ }^{(21)}$. Os clientes internados em CTI podem desenvolver ansiedade devido a fatores como a ameaça de desamparo; perda de controle; sensação de perda de função e auto-estima; falha de defesas anteriores; sensação de isolamento e medo da morte ${ }^{(21)}$

Assim, pode-se inferir que a questão do isolamento social do cliente de CTI está diretamente relacionada ao afastamento familiar e ao ambiente de morte. As ações que colaboram para que esse quadro possa ser minimizado, durante a internação nesse setor, 
são: a proximidade e o envolvimento dos membros da família, o estabelecimento de vínculo e a orientação por parte da equipe de enfermagem, e, ainda, a permissão para que $o$ cliente participe e opine sobre seu tratamento ${ }^{(21)}$.

Conclui-se, então, estar em poder da enfermagem, enquanto profissão que enfatiza o tratamento personalizado e holístico, realizar as ações que poderiam viabilizar o entendimento e a compreensão da internação em CTI, tanto por parte dos clientes quanto da família. Dessa forma, acredita-se que o processo de internação, nesse ambiente, possa tornar-se menos agressivo e traumatizante a seus usuários.

CTI: o elo entre a beira do abismo e a liberdade

Nessa categoria, estão representados os depoimentos dos clientes e de seus familiares a respeito de como eles compreendem o cuidado e o ambiente do CTI. Os relatos destacam, de maneira geral, características relativas à estrutura e ao funcionamento do setor. Assim, surgiram duas subcategorias: ambiente seguro e higiênico e o ambiente frio e fechado.

Ambiente seguro e higiênico

Nessa subcategoria, os depoimentos demonstram, de maneira geral, que o cliente internado no CTI tem uma visão completa do ambiente. A concepção que ele tem é de um ambiente agitado, mas que, em determinados momentos, promove tranqüilidade.

Os clientes e familiares conseguem identificar e descrever as rotinas inerentes ao setor e enfatizam que, após a sua realização, o ambiente torna-se "tranqüilo" e "sossegado", o que, de certa forma, é o que eles esperam e consideram como fator primordial à recuperação.

... A UTI, até certa hora, quando tem alguém passando mal, ai tem barulho. Mas, depois que medica todo mundo, entra em silêncio e a gente fica tranqüila. De dia, o barulho é até normal, todo mundo está trabalhando... (Cliente 10).

Outro aspecto que aparece nos relatos e merece ser destacado diz respeito a características de limpeza e organização. Por permanecer um grande período no CTI, o cliente percebe as rotinas do setor. Esse ambiente "bombardeia" o cliente 24 horas por dia e, além da preocupação com os estímulos ambientais, ele enfrenta os medos relacionados à doença ${ }^{(21)}$, fato esse que, muitas vezes, não se aplica aos familiares, uma vez que eles permanecem por um curto período de tempo dentro do setor, em momentos em que poucas atividades são desenvolvidas.

Portanto, pode-se afirmar que todos esses fatores relacionados ao ambiente, à limpeza, à organização, ao conforto e à orientação do cliente internado no CTI facilitam a compreensão do cliente e da família em relação ao atendimento seguro e eficaz do setor. Esses aspectos promovem o envolvimento e uma conseqüente integração do cliente e dos familiares com o CTI. Propiciam a essas pessoas a percepção desse local como especializado ao atendimento e recuperação de clientes graves, porém com atendimento que oferece segurança e tranqüilidade.

Um fator que mostra a segurança no CTI está vinculado à questão do cuidado direto $\mathrm{e}$ especializado oferecido ao cliente pela equipe. Aspectos que demonstram essa peculiaridade do CTI estão ligados a fatos como a presença 
constante da equipe, a sua proximidade em relação ao cliente, a existência de um profissional para atender a cada cliente individualmente e ainda a questão do preparo e da vivência prática da equipe, como demonstram os relatos.

... Quando eu acordei na UTI eu vi que estava bem ... o atendimento que você tem lá dentro te deixa mais segura ... você pode ficar tranqüila, pode dormir tranqüila porque você sabe que está tendo uma assistência, que tem sempre alguém do seu lado te olhando. Qualquer coisa, eles tão ali. (Cliente 6).

... Eu achava que aqui era mais simples. E aqui é muito bem organizado, muito bem equipado. Parece que o pessoal é muito preparado (Família 11).

Os profissionais de enfermagem têm papel definidor no que diz respeito à confiança e credibilidade dos clientes com relação ao ambiente e ao tratamento oferecido no CTI.. Por meio das ações desses profissionais, os clientes e sua família identificam-no como agressivo ou tranqüilo.

Portanto, destaca-se a assistência de enfermagem como fundamental ao atendimento de necessidades básicas que envolvem segurança e confiança dentro do contexto de internação em CTI.

\section{O ambiente frio e fechado}

Nessa subcategoria, contrariamente à primeira, os relatos mostram a internação em CTI como um fator negativo ao cliente e sua família, uma vez que o ambiente não se mostra adequado para receber e tratar pessoas que necessitam de tranqüilidade para a recuperação.

Os clientes entendem que fatores como barulho, movimentação excessiva, excesso de luminosidade e de ventilação são considerados incômodos e contribuem para prejudicar o cuidado oferecido.

O CTI é um ambiente em que o cliente não recebe estímulos provenientes do meio exterior. Tanto a iluminação como a ventilação são artificiais. Portanto, a noção de tempo e espaço é extremamente prejudicada.

Pode-se afirmar que o cliente hospitalizado sofre um processo de "separação do mundo", em que ocorrem mudanças significativas nos hábitos de higiene, de alimentação, de eliminação, de sono e repouso, de carinho, de convivência familiar e nos aspectos relacionados ao trabalho.

... na minha casa eu durmo no escuro mesmo, não fica nenhuma luz acesa e aqui, já está doente, tem a preocupação se vai melhorar, se não vai. E aí a claridade atrapalha o sono ... (Cliente 10).

Vários são os fatores que contribuem para o significado cultural atribuído ao CTI como um local fechado e isolado. Os relatos ressaltam essa questão quando os clientes e os familiares utilizam expressões que a evidenciam, tais como: ambiente de isolamento do cliente com um ser doentio; ambiente propício para clientes graves em estado terminal; e a caracterização do CTI como ambiente fechado. A entrada de pessoas nesse local é restrita e limitada, e as informações que chegam aos que estão do lado de fora nem sempre refletem a realidade ou não são compreendidas, ficando os familiares sem saber o que realmente acontece lá dentro.

A rotina estabelecida para as visitas no CTI apresenta aspectos positivos e negativos para o cliente e a família, sendo que dois fatores são levados em consideração: o cliente recebendo sua família e a limitação do horário estipulado para a realização das visitas.

Os relatos mostram claramente que, 
tanto para os clientes como para a família, o horário de visitas é tido como fator imprescindível à internação em CTI, uma vez que o afastamento e a separação entre estes podem ser considerados como fatores geradores de estresse e insegurança. Assim, o horário de visitas contribui significativamente para acalmar o cliente e a família. Somente pela observação direta e da presença do familiar é que o cliente se considera seguro e assim entende que, além dele, a família também vivencia seu processo de doença, internação e tratamento.

... Então eu acho que o horário das visitas é muito importante porque a família geralmente fica preocupada, então quanto mais eles aproximar do paciente, é mais importante, tanto para o paciente quanto para eles. Para família (Cliente 4).

... Eu fiquei tranqüila, porque, antes de eu vir, eu fiquei muito chocada porque me falaram que ele tinha sofrido um infarto. Então eu assustei muito, fiquei muito abalada, mas, depois que eu vi ele, fiquei mais tranqüila (Família 9).

Percebe-se, então, que o horário de visitas é um aspecto de muita relevância para - cliente e para a família, devendo ser observado e analisado atentamente pela equipe de enfermagem, na tentativa de aproximar os interesses do cliente, da família e do CTI.

Os profissionais de saúde a serviço do bem-estar do cliente devem estar atentos a questões como estas, pois a família é considerada como parte integrante do contexto do cliente e possui direitos em relação à hospitalização do seu ente.

A alta do CTI: a liberdade para a vida

Nessa categoria, encontra-se os depoimentos dos clientes e familiares que expressam momentos íntimos de reflexão, dos quais emergem sentimentos de valorização da vida e gratidão a Deus por terem vivenciado a internação no CTI e vencido essa etapa. Assim, destacam-se duas subcategorias que surgiram dos dados, durante a análise: a alta do CTI: o encontro com Deus e a alta do CTI: o recomeço da vida.

A alta do CTI: o encontro com Deus

A questão da espiritualidade, independente da crença religiosa da pessoa, é um aspecto marcante para os clientes e seus familiares, durante a vivência do CTI. A fé em Deus aparece nos relatos e representa, para os clientes, um aspecto importante que permeia todo o processo de internação nesse setor.

Pode-se observar, nos depoimentos, que os clientes que vivenciam, na íntegra, de maneira rotineira, todos os aspectos positivos e negativos inerentes à internação no CTI enaltecem a crença e a fé em Deus, como entidades diretamente vinculadas ao processo de internação e à alta.

A espiritualidade inclui o sistema de crenças e valores da pessoa. A intuição e o conhecimento de fontes desconhecidas são entendidos como capacidade espiritual inerente à pessoa. Esta se manifesta como sensação de conexão universal, capacitação pessoal e reverência pela vida ${ }^{(21)}$.

... Ai eu andei lendo. Eu não gosto de ler revista, eu não gosto de nada, sabe, e a Bíblia me acalma muito (Cliente 10).

... Quando eu fiquei sabendo que ela infartou, eu rezei muito para Deus e pedi para que ele desse força para ela recuperar e sair dessa. A gente tem os pedaços ruins, mas a gente sai ... foi o que eu fiz (Família 13).

Com relação à presença da fé e da 
espiritualidade, durante o período de internação no CTI, observou-se que elas estão sempre presentes. Vários aspectos lembram, a todo o momento, a presença de Deus. Ao entrar no hall que dá acesso aos leitos, encontram-se uma imagem e algumas flores artificiais. Nas enfermarias, podemos observar a presença constante de água benta e ungüentos trazidos pelos familiares, bíblias e livros sagrados e ainda amuletos (medalhas) fixados no lençol do cliente. É constante, ainda, a presença de um padre que, duas vezes por semana, vem "abençoar" os clientes, independente de sua crença religiosa. Também é freqüente o pedido dos familiares para a autorização da entrada de oradores para rezar ao lado dos parentes. Ao que parece, a fé e a presença de Deus, por meio dos religiosos, traz um conforto e confiança à família e ao cliente.

Durante o processo de alta, a família reforça os laços com o cliente, por meio dos rituais e infortúnios. Esses se fundamentam em uma abordagem moral e religiosa de controle da situação. Os rituais podem estar presentes em qualquer ambiente, sendo representados por orações, gestos de afeto, novenas e amuletos $^{(16)}$.

Assim, a presença de Deus e o significado da crença em um ser superior, como mediador dos momentos de conflito e sofrimento, durante a internação, assinalam a passagem dos clientes pelo CTI. Para eles, somente a fé, associada à presença de um ser superior, tem o dom e o poder da cura, da aceitação e da resignação, sentimentos que colaboram para minimizar os efeitos nocivos de internação em CTI.

Dessa maneira, como demonstrado nos relatos, a presença de Deus, de um ser sagrado, está diretamente relacionada à questão da cura e da gratidão. O próprio cliente evidencia sua fé e a descreve como benéfica. Este parece entregar a Deus a responsabilidade, a decisão pela sua vida ou morte; como se a justiça divina demonstrasse todo seu poder por intermédio dos médicos.

... Eu não sei se foi a minha fé, ou se foi a força de vontade do médico e eu passei a escutar o meu coração. Fui melhorando. Eu pedi muito a Deus, eu sou uma pessoa religiosa. Melhorei tanto que estou aqui ... porque eu conversei muito com Deus. Deus colocou as mãos naquele remédio que ele aplicou e estou aqui no quarto, graças a Deus (Cliente 10).

... eu não conheço outra UTI para falar, porém, ali para mim é igual uma igreja ... eu diria que hoje eu considero a UTI um lugar sagrado para o paciente. Mais, sagrado do que às vezes para certos cristãos que existe por ai, do que a própria igreja ... (Cliente 17).

O sagrado pode ser entendido como "instrumento de sobrevivência" do ser humano, que busca, pela crença e fé, a garantia da vida. $\mathrm{O}$ encontro com Deus representa um apelo à liberdade e à "intenção" de cada indivíduo ${ }^{(22)}$.

A alta do CTI: o recomeço da vida

O período de internação e alta do CTI, além de aproximar o cliente de Deus, aflorando sua fé, contribui também para que este possa refletir sobre os valores já apreendidos. Portanto, significa um recomeço da vida, momento em que tudo é repensado.

Quando o cliente percebe que passou pelo CTI, é como se "uma vida nova estivesse começando" ${ }^{\text {"(20) }}$. O fato de estar vivo tem muita importância para os que vivenciaram o processo de internação, bem como a presença da família, pois ela reafirma laços afetivos e fortalece o reencontro com a vida.

Os relatos demonstram que a alta 
representa um "incentivo" concedido por Deus para o recomeço da vida. Este representa o momento em que eles reconhecem o real significado de estar vivo, e passam a valorizar mais a vida.

... eu sentia medo antes de conhecer a UTI, ... eu acho que é um aprendizado muito grande, é um incentivo de vida, principalmente vendo pessoas no estado que eu vi ali dentro. Eu acho que a gente aprende muito. O que significou para mim foi isso, eu ter aprendido a valorizar mais a minha vida (Cliente 6).

... Então a gente fica pensando, esse negócio dela estar aqui no CTI, eu quase morri. Para falar a verdade, quando a minha mãe sair desse hospital, que for para casa, acho que ela pode falar 'vivi de novo' (Família 15).

Considerando a valorização da vida após a vivência do $\mathrm{CTI}$, esse ambiente pode estar associado tanto à questão da morte e da finitude, como também à questão do renascer. Esse contraste de idéias fundamenta-se na "fantasia", criada antes da internação no CTI e, na realidade, vivenciada nesse ambiente, demonstrando que o cliente expressa uma relação íntima entre a vida e a morte ${ }^{(20)}$.

Os depoimentos mostram, ainda, que a internação no CTI transcorre de maneira que quem passa por essa experiência, quando recebe alta, desenvolve um sentimento de gratidão a Deus por mais uma etapa vencida.

Embora, na maioria das vezes, a hospitalização possa significar uma interrupção na vida cotidiana, também pode ser entendida como uma oportunidade positiva para o crescimento das pessoas e para a valorização da vida(18).

Para os clientes, o CTI significa um "elo entre a beira de um abismo e a liberdade", ou seja, significa muito mais do que um local com assistência especializada, destinado a receber clientes graves, para tratamento adequado e específico. A internação, nesse setor, representa o vínculo entre a vida e a morte.

... A UTI foi um elo da beirada de um abismo para a liberdade. Porque do jeito que eu cheguei e do jeito que eu saí. Então significa isso, que você está caindo no abismo e de repente alguém te dá a mão e te bota numa parte segura e tudo ... um elo de estar se perdendo e conseguir se livrar. A explicação mais lógica é essa (Cliente 8).

... E recomeçar a vida de outro jeito, acreditando mais em Deus principalmente ... Porque eu rezei muito (Família 15).

Assim, após vivenciar o CTI, os sentimentos que emergem dos clientes e seus familiares estão diretamente relacionados ao agradecimento pela vida e à gratidão a Deus. O CTI passa a possuir significado espiritual para estes, sendo considerado como "lugar onde se pode encontrar Deus".

Dessa forma, a passagem pelo CTI significa "recomeçar a vida acreditando mais em Deus", dando valor ao bem mais precioso que Deus nos concedeu: a vida.

\section{TEMA CULTURAL}

Descrevemos a seguir o tema cultural, o qual teve origem a partir da construção e da análise das categorias descritas anteriormente. Portanto, pode-se ressaltar que, diante do objetivo do estudo e da análise dos dados, o tema cultural identificado, a partir da construção das categorias, foi: "o significado atribuído ao CTI por clientes e seus familiares: um elo entre a beira do abismo e a liberdade".

Cada pessoa tem uma cultura particular, desenvolvida ao longo do tempo. Essa cultura influencia diretamente aspectos de sua vida que dizem respeito às crenças, comportamentos, 
percepções, emoções, línguas, religiões e, dentre outros, as atitudes em relação à doença $^{(11)}$.

Considerando-se a cultura que envolve os informantes, o CTI é entendido enquanto um lugar desconhecido e assustador, que, ao mesmo tempo, significa a valorização da vida, representada pelo elo entre a beira do abismo e a liberdade para se viver.

Nessa perspectiva, considera-se importante a compreensão dos MEs utilizados por clientes e familiares para explicar a enfermidade e o processo de internação no CTI. A interação entre os MEs (leigo e médico) possibilita uma melhor comunicação entre as pessoas, contribuindo para moldar o relacionamento entre a equipe, o cliente e a família, minimizando os efeitos negativos da internação ${ }^{(14)}$.

Portanto, entende-se que ações simples como o toque, a conversa, a informação técnica referente ao setor, a informação biológica referente ao cliente e a empatia dos profissionais possam contribuir, significativamente, para amenizar os efeitos nocivos da internação em CTI, evidenciando, assim, os aspectos positivos para os clientes e seus familiares, facilitando, desse modo, o processo de internação.

\section{REFERENCIAS BIBLIOGRÁFICAS}

1. Koizumi MS. Percepção dos pacientes de Unidade de Terapia Intensiva: problemas sentidos e expectativas em relação à assistência de enfermagem. Rev Esc Enfermagem USP 1979; 13(2):135-45.

2. Kurcgant $P$. Formação e competência do enfermeiro de Terapia Intensiva. Rev Enfoque 1991 abril; 19(1):4-6. 3. Kimura M. Problemas dos pacientes de Terapia Intensiva: estudo comparativo entre pacientes e enfermeiros. [dissertação]. São Paulo (SP): Escola de Enfermagem/USP; 1984.

4. Takahashi EIU. Visitas em unidade de terapia intensiva. Rev Paul Enfermagem 1986 julho/agosto/setembro; 6(3):113-5.
Portanto, considera-se extremamente relevante o entendimento do tema deste estudo, por parte dos enfermeiros intensivistas que possuem como objetivo de trabalho conhecer e fundamentar suas atividades no "cuidado" personalizado e individualizado ao cliente e à família que vivenciam o processo de internação em CTI, fundamentando-se no contexto cultural destes.

Este estudo não teve como propósito esgotar o tema acerca da compreensão do significado cultural atribuído à internação em CTI, mas, delimitar um caminho a ser percorrido pela enfermagem e pelos profissionais da área de saúde, no qual esteja clara a necessidade de informação e de humanização em relação ao cuidado. Acredita-se que, pela compreensão do significado da internação em CTI, para o cliente e sua família, a enfermagem possa trilhar dignamente esse caminho, considerando, assim, a cultura que envolve esse grupo. Assim, poderá elaborar um plano de ação específico, em que não ocorra a imposição da cultura do enfermeiro sobre a do grupo em questão. Esses fatores certamente irão contribuir para que um grande passo seja dado em relação à qualidade da assistência oferecida pela enfermagem e para a desmistificação do CTI por parte dos clientes e seus familiares.

5. Chavez CW Effect of an education-orientation program on family members who visit their significant other in the intensive care unit. Heart \& Lung 1987; 16(1):92-9.

6. Waters CM. Professional Nusing Support for culturally Diverse Family Members of Critically III Adults. Res Nurs \& Health 1999; 22(2):107-17.

7. Peixoto MRB. A prioridade, o Isolamento e as Emoções: estudo etnográfico do processo de socialização em um centro de Tratamento Intensivo. [tese]. São Paulo (SP): Escola de Enfermagem/USP; 1996.

8. Castro DS. Estresse e Estressores dos Familiares de Pacientes com Traumatismo crânio-encefálico em Terapia Intensiva. [tese]. Ribeirão Preto (SP): Escola de Enfermagem de Ribeirão Preto USP; 1999. 
9. Maciel ICF. Sentimentos e Expectativas da paciente acerca do tratamento na Unidade de Terapia Intensiva. [monografia]. Fortaleza (CE): Universidade Estadual do Ceará; 1996.

10. Scarelli EM. Orientação à família do paciente internado em Unidade de Terapia Intensiva. [dissertação]. Ribeirão Preto (SP): Escola de Enfermagem de Ribeirão Preto/USP; 1993.

11. Helman CG. Cultura Saúde e Doença. $2^{\mathrm{a}}$ ed. Porto Alegre (RS): Artes Médicas; 1994.

12. Gualda DMR, Holga, LAK. Pesquisa Etnográfica em Enfermagem. Rev Esc Enfermagem USP 1997 dezembro; 31(3):410-22.

13. Minayo MCS. O desafio do conhecimento: pesquisa qualitativa em saúde. $5^{\text {a }}$ ed. São Paulo (SP): HucitecAbrasco; 1998.

14. Germain C. Ethnography: the method. In: Munhall PL, Boyd OC Nursing Research: a qualitative perpective. $2^{\text {a }}$ ed. New York: National League Nursing Press; 1986.

15. Morse JM, Field PA. Qualitative Research Methods for Health Professionals. $2^{\mathrm{a}}$ ed. Thousand Oaks: SAGE Publications; 1995.

16. Kleinman A. Patients and healers in the contest of culture An exploratory of the borderland between antropology, medicine and psychiatry. Berkeley/Los Angeles: University of California Press; 1980.

17. Oliveira LMAC Assistência de Enfermagem à família na UTI - uma abordagem sobre o atendimento de suas necessidades. [dissertação]. Rio de Janeiro (RJ): Escola de Enfermagem Anna Nery/UFRJ; 1991.

18. Armelin MVAL. Apoio emocional às pessoas hospitalizadas. [tese]. Ribeirão Preto (SP): Escola de Enfermagem de Ribeirão Preto/USP; 2000.

19. Graças EM. A experiência da hospitalização: uma abordagem fenomenológica. [tese]. São Paulo (SP): Escola de Enfermagem/USP; 1996.

20. Guirardello EB, Gabriel CAAR, Pereira IC, Miranda AF. A percepção do paciente sobre sua permanência na Unidade de Terapia Intensiva. Rev Esc Enfermagem USP 1999 junho; 33(2):123-9.

21. Hudak CM, Gallo BM. Cuidados Intensivos de Enfermagem: uma abordagem holística. $6^{\mathrm{a}}$ ed. Rio de Janeiro (RJ): Guanabara Koogan; 1997.

22. Bello AA. Culturas e Religiões: uma leitura fenomenológica. São Paulo (SP): EDUSC; 1998. 